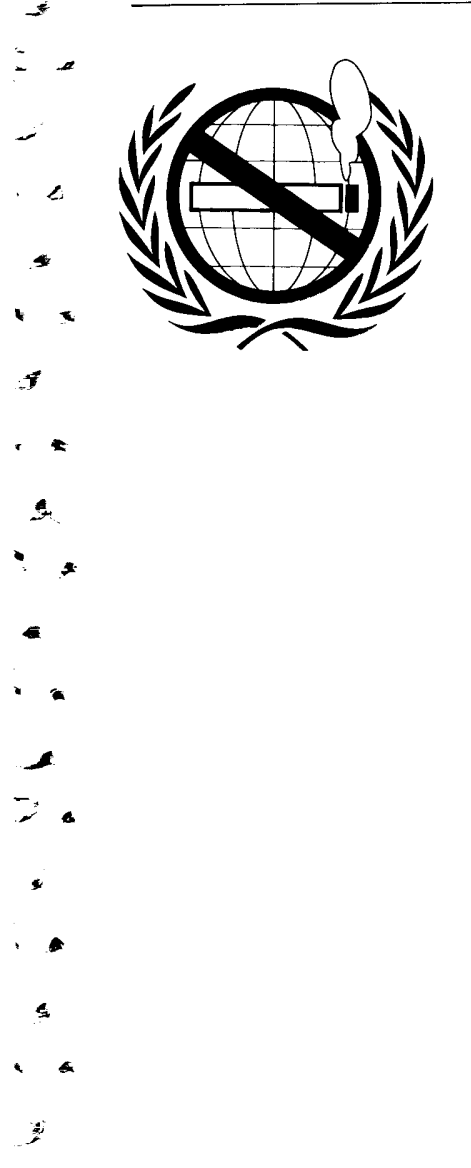

\title{
Spotlight on tobacco-or-health issues in Côte d'Ivoire
}

Early in 1993, the Minister of Health and Social Protection of Côte d'Ivoire, Professor Alain Ekra, became convinced that something had to be done to stem increasingly aggressive tobacco marketing in his country, and he asked the World Health Organisation (WHO) if it could help. WHO responded by sending an expert from the Tobacco or Health Programme in Geneva to Abidjan in April 1993. Together, local WHO officials, the Minister and his staff, and the representative from WHO Headquarters got to work on addressing the problems and beginning to implement solutions. Their work resulted in a final report with recommendations, which was presented to Minister Ekra on 27 April 1993.

Côte d'Ivoire, along with many other countries of sub-Saharan Africa, represents the world's last best hope for true primary prevention of an epidemic of tobacco-attributable disease and death. While few data are available, most indicators point to low levels of tobacco consumption. For 1990, it was estimated that cigarette consumption, overwhelmingly the most important form of tobacco consumption in the country, stood at 508 cigarettes per person 15 years of age and over. ${ }^{1}$ Only one prevalence survey has been carried out, and that only in the urban population of the largest city, Abidjan. It was reported that $42 \%$ of men and only $2 \%$ of women were smokers in the surveyed population in Abidjan in $1977 .{ }^{2}$ Worsening economic conditions in the Côte d'Ivoire were associated with a $40 \%$ decline in cigarette consumption per adult from 1977 to 1990. In these circumstances, the WHO team estimated current smoking prevalence to be in the range of $20 \%-40 \%$ among men and $1 \%-2 \%$ among women. Low rates of per capita tobacco consumption and low rates of prevalence, particularly among women, should make the prevention of a large-scale tobacco epidemic possible in Côte d'Ivoire. In Europe and North America, smoking prevalence often exceeded $60 \%$ among men and $40 \%$ among women in the 1950s and 1960s. Now, about one in five deaths in these regions is caused by tobacco. Côte d'Ivoire, by stopping tobacco use before it becomes more widespread, can largely avoid the tragedy of the tobacco epidemic that is now sweeping most of the world.

Action can't come fast enough. If public health officials have identified Côte d'Ivoire as an area where primary prevention of a tobacco epidemic is possible, it is equally true that multinational tobacco companies have identified it as fertile ground for aggressively marketing their deadly products. A tobacco advertisement sits atop the highest building in
Abidjan. But tobacco is also aggressively marketed at street level through thousands of tables under parasols advertising tobacco merchants' wares that line the thoroughfares of Côte d'Ivoire. There is nothing subtle about tobacco advertising billboards depicting European or North American smokers offering to share their addiction by offering cigarettes to young Africans. Sponsorship of sports and arts by tobacco companies knows no bounds. Soccer, other sports, music concerts, and theatrical events all accept tobacco money in exchange for helping to promote these deadly products. Compounding the growing presence of tobacco advertising is the growing problem of cigarette smuggling, estimated to account for about $13 \%$ of total cigarette consumption.

Minister Ekra, who must deal with numerous other important health problems in Côte d'Ivoire, including AIDS, water-borne diseases, malaria and other tropical diseases, was nevertheless quick to recognise the importance of primary prevention of a tobacco epidemic. By investing a little in primary prevention now, costly attempts to control it later would be completely avoided. Moreover, a small investment in tobacco control measures now need not upset current major health priorities in Côte d'Ivoire. He quickly responded to a key recommendation of the WHO team and named an experienced physician in the Department of Health and Social Protection, Dr Sehiri Darret, to work full-time on developing tobacco control strategies for the Côte d'Ivoire.

No time was lost. Dr Darret and members of the WHO team visited key health professionals concerned about tobacco use. A visit was paid to the Director-General of the Sociéte ivoirienne du Tabac (SITAB), the only tobacco manufacturer in the country. Key visits were also paid to journalists at two of Abidjan's many newspapers, senior officials of two airlines, and the railroad company. All were informed that the Minister of Health wished to undertake a national strategy to discourage tobacco use, and that they could all contribute to the success and coherence of a national tobacco control policy. Enthusiastic support was received from the health, journalism, and transportation milieu. Ministries of Education, Youth and Sport, and Industry and Commerce were also contacted. All agreed to do what they could to contribute to a national policy to prevent a tobacco epidemic in the Côte d'Ivoire.

Will Côte d'Ivoire succeed where others have failed in stemming the tide of a worldwide tobacco epidemic? Only time will tell. But at least tobacco control in Côte d'Ivoire is off to 
a good start. Thanks to the public health foresight of the Health Minister, Dr Ekra, Côte d'Ivoire now has a full-time physician working on tobacco control within the Ministry. With a little help from WHO, Dr Darret has embarked on seeking the implementation of an ambitious set of recommendations that would make Côte d'Ivoire a world leader in tobacco control.

1. Societé Ivoiriennie du Tabac, unpublished data, 1993.

. Schmidt D, Dialio AD, Tiendrebeogo $H$, Roudaut $M$. Enquête sur la consommation tabagique en milieu africain à Abidjan. Poumon-Coeur 1981; 37: 87-94. 